\title{
Synthesis and X-ray Powder Diffraction Characterization of $\mathrm{Ca}_{12} \mathrm{Ga}_{14} \mathrm{O}_{33}$
}

Claudia J. Rawn ${ }^{1,2}$, John Robert Salasin ${ }^{3}$, and Sabrina E.A. Schwerzler ${ }^{1,2}$

${ }^{1}$ Materials Science and Engineering Department, University of Tennessee, Knoxville, TN 37996 USA

${ }^{2}$ Center for Materials Processing, University of Tennessee, Knoxville, TN 37996 USA

${ }^{3}$ BWX Technologies, Inc., Lynchburg, VA 24501 USA

\section{Email Contact: crawn@utk.edu}

$\mathrm{Ca}_{12} \mathrm{Al}_{14} \mathrm{O}_{33}$, also known as $\mathrm{C} 12 \mathrm{~A} 7$, consists of a positively charged cage-like structure with occluded anions occupying one out of every six cages to charge balance the positively charged framework. The occluded anion gives rise to the highly function nature of the material and raises questions about isostructural compounds and their potential properties. Framework distortions are correlated to changing the electrical properties from a wide band gap insulator to metallic conductor in electride C12A7 systems so it is possible that alteration of Al cations in the electride structure may lead to changes in physical properties. The existence of $\mathrm{C} 12 \mathrm{G} 7$ has been theorized due to the similarity of the $\mathrm{CaO}-\mathrm{Al}_{2} \mathrm{O}_{3}$ and $\mathrm{CaO}-\mathrm{Ga}_{2} \mathrm{O}_{3}$ binary phase diagrams, however, attempts to synthesize $\mathrm{C} 12 \mathrm{G} 7$ through solid state techniques has only resulted in formation of the C5G3 phase [1]. Using wet chemistry techniques single phase $\mathrm{C} 12 \mathrm{G} 7$ has been successfully synthesized. X-ray powder diffraction data of the C12G7 has been collected and analyzed using the Rietveld method. The refined lattice parameter for C12G7 is 12.2991 (3) $\AA$, approximately $2.5 \%$ larger than the lattice parameter of C12A7.

References

[1] A. S. Tolkacheva et al., "Synthesis, Structure, and Thermal Properties of $\mathrm{Ca}_{5} \mathrm{Ga}_{6} \mathrm{O}_{14}$," Russ. J. Phys. Chem. A, vol. 92, no. 7, pp. 1243-1247, 2018. 